\title{
SHRINK STOPE DESIGN USING AN INVENTORY MODEL
}

\author{
Danny Taylor \\ Mackey School of Mines, University of Nevada \\ Reno, Nevada, 89557, U. S. A. \\ And \\ Robert E. D. Woolsey \\ Mathematics Department, Colorado School of Mines \\ Golden, Colorado, 80401, U. S. A.
}

\begin{abstract}
This paper addresses the fact that current practice in shrink-stoping in hard rock mining invariably ignores the inventory holding cost of the blasted ore. We believe, and show by example, that ignoring this cost could make the difference between profit and loss in an industry that, at present, needs all the help it can get.
\end{abstract}

\section{INTRODUCTION}

This paper treats a real-world problem in hard-rock mining in a unique way. In shrink stope mining, the broken ore remaining after a blasting operation stays in the stope and is usually considered an inventory. We will model this quantity with the classical Economic Order Quantity method. We do not assert that the EOQ method is the best, or even a good 
model for this situation. It is just a first step in bringing management's attention to possible trade offs between the holding and set-up costs in this problem. We wish to define an optimum stope size that will both minimize the sum of holding costs and development costs. After some analysis, we show that ignoring the holding cost of the above inventory, can cause significant underestimation of the actual total cost of shrink-stoping.

\section{PROBLEM STATEMENT}

Consider a shrink stoping operation with the following data:

$\mathrm{Q}=$ size of the stope block in tonnes

$\mathrm{R} 1=$ rate at which ore is broken in the stope

$S=\%$ swell for broken ore expressed as a decimal fraction

$\mathrm{T} 1=$ time needed to break all of the ore in a stope, $=\mathrm{Q} / \mathrm{R} 1$

$\mathrm{Q}^{*}=$ tonnes of broken ore in stope after $\mathrm{T} 1,=\mathrm{Q}(1-\mathrm{S})$

$\mathrm{T} 2=$ time to pull the stopes after all ore is broken

$\mathrm{R} 2=$ draw rate of ore during $\mathrm{T} 2,=\mathrm{Q}^{*} / \mathrm{T} 2$

$R=$ average rate of production for the stope $=(T 1 R 1+T 2 R 2) /(T 1+T 2)$

Then the maximum inventory in a stope is $\mathrm{Q}^{*}$ and the average inventory is $\mathrm{QAVE}=\mathrm{Q}^{*} / 2$, so that the average inventory holding cost is $\mathrm{CiQ}^{*} / 2$. We define $\mathrm{Ci}$ as the "part-period" holding cost with units of Rand per ton per unit time. Since the broken ore as a stock on hand represents a lost opportunity cost, $\mathrm{Ci}$ will be the company's cost of money times the cost to break the ore.

The other part of the total expected cost equation is the average set-up cost or development $\operatorname{cost}(\mathrm{Cs} R) / \mathrm{Q}$ where $\mathrm{Cs}$ is the cost to develop a block of size $\mathrm{Q}$. Operating costs over the 
range to be considered are most dependent on outside factors such as vein width, dip, ore hardness, etc., and will not vary significantly with the size of the stope block. We then have the usual cost equation to be optimized as:

$T E C=C i \cdot Q \cdot(1-S) / 2+C s \cdot R / Q$,

If $\mathrm{Cs}$ could be determined as a constant, this equation could be easily solved, giving the well-known square-root Economic Order Quantity, below:

$$
\begin{aligned}
& Q_{o p t}=\sqrt{(2 \cdot C S \cdot R) /(C i \cdot(1-S))}, \\
& T E C_{o p t}=\sqrt{2 \cdot C i \cdot(1-S) \cdot C S \cdot R},
\end{aligned}
$$

However, Cs is not a constant and depends on the stope geometry. We can break down the development costs into three components: vertical costs, horizontal costs and fixed costs. Vertical costs are those varying directly with the height of the stope, such as raise construction. Horizontal costs are those varying with the length of the stope such as undercutting and drawpoint construction. Fixed costs include stations at the top and bottom of raises and all other stope development that does not vary with the size of the block. If we represent these costs as $\mathrm{Ch}, \mathrm{Cl}$ and $\mathrm{Cf}$, and the block height and length as $\mathrm{H}$ and $L$, then:

$C s=C 1 \cdot L+C h \cdot H+C f$,

and

$Q=L \cdot H \cdot W \cdot D$,

where $\mathrm{W}$ is the vein width, and $\mathrm{D}$ is the density of the ore. Then our objective function 
becomes:

$\operatorname{Min} T E C=C i \cdot(1-S) W D H L / 2+(C 1 \cdot L+C h \cdot H+C f) \cdot R /(W D H L)$,

Expanding and simplifying, this becomes:

$T E C=C i \cdot(1-S) W D H / 2+C h \cdot R / W D L+C 1 \cdot R / W D H+C f / R / W D H L$,

\section{CASE I. VERTICAL LEVEL INTERVAL IS FIXED}

We first assume that the vertical interval level is fixed. Such a situation would occur in an existing operation where the working level interval has already been established or in a new operation where this vertical distance is fixed by factors such as rock mechanics, hydrology, structural control, etc. In this case $\mathrm{H}$ is a constant and total expected cost is then:

$T E C=C i \cdot(1-S) W D H L / 2+(C h \cdot R+C f \cdot R / H) /(W D L)+C 1 \cdot R /(W D H)$,

Since the last term is a constant, we can define TEC' $=$ TEC - CIR/WDH. So that:

$T E C=C i \cdot(1-S) W D H L / 2+(C h \cdot R+C f \cdot R / H) / W D L$,

This is a "by inspection" problem with geometric programming, which gives:

$$
\begin{aligned}
& T E C^{\prime}{ }_{\text {opt }}=\sqrt{(2 \cdot C i \cdot(1-S) \cdot H \cdot(C h+C f / H) \cdot R)}, \\
& T E C_{\text {opt }}=T E C_{\text {opt }}{ }+C 1 \cdot R / W D H,
\end{aligned}
$$




$$
\begin{aligned}
& L_{o p t}=\sqrt{\frac{(2 \cdot(C h+C f / H) \cdot R)}{\left(C i \cdot(1-S) \cdot W^{2} \cdot D^{2}\right)^{\prime}}}, \\
& Q_{o p t}=D \cdot W \cdot H \cdot L_{o p l}
\end{aligned}
$$

\section{EXAMPLE I.}

Let us assume that we have a width of 10 meters, a vertical dip, a density of .083 tonines/cubic meter, a swell of $33 \%$, and a level interval of 100 meters. The deposit is to be mined by longitudinal shrink stopes developed by 6 by 10 meter raises in 10 by 36 meter ore pillars with access from the raises on $\mathbf{2 5}$ meter intervals. Horizontal development is from an in-vein system with a 10 by 10 meter undercut located 30 meters above the haulage sill. Loading will be through chutes connected to the undercut by finger raises on 25 meter centres.

We also assume the following costs:

$\mathrm{Ch}$, (costs relating to block height): raise construction, conventional @ R100/meter equipped; stope access, stub drifts @ R1000 each or R40/meter. $\mathrm{Cl}$, (costs relating to block length: undercut construction @R150/meter, finger raise and chute construction @ R1250 each or R50/meter.

Cf, (fixcd costs): raise station construction @ R5000

In shor $\mathrm{Ch}=\mathrm{R} 140 /$ meter, $\mathrm{Cl}=\mathrm{R} 200 /$ meter, and $\mathrm{Cf}=\mathrm{R} 5000$

Finally, let the company's discount rate be $12 \%$ and the breaking cost of the ore is $\mathrm{R} 50 /$ tonne, then $\mathrm{Ci}=50 \times 0,12 / 12=\mathrm{R}, 50 /$ tonne/month. Further, let the average production rate per stope be 2000 tonnes/month. Solving we have:

$T E C_{\text {opt }}^{\prime}=R 5046, T E C_{\text {opt }}=R 5046+R 4800=R 9846$. 
$L_{\text {opt }}=180$ meters, $Q_{\text {opt }}=15100$ tonnes

The contributions to monthly costs are:

$\begin{array}{lll}\text { Cost Source } & \% & \% \times \text { TEC } \\ \text { Inventory } & 25 & 2523 \\ \text { Vertical Development } & 18 & 1892 \\ \text { Raise Stations } & 07 & 0631 \\ \text { Horizontal Development } & 50 & 4800 \\ \text { Total } & 100 & 9846\end{array}$

In this example, we can note that the horizontal development cost per month are constant at $\mathrm{ClR} / \mathrm{DWH}=\mathrm{R} 4800$. Therefore since this is a zero degree of difficulty geometric programming problem, the variable actual development costs are always equal to the inventory holding costs at optimality. It should be noted that most shrink stope designs are done ignoring an inventory cost equal to the cost implied by the physical layout.

\section{CASE II.}

Next consider the situation where the vertical level interval is not predetermined, that is, $\mathrm{H}$ is also a design variable: We now have two variables and four terms giving a 1 degree of difficulty geometric programming problem. (For a discussion of geometric programming methods, see Woolsey [2].) Such 1 degree of difficulty problems, although complicated, can be solved, and easily evaluated on a small computer or even a programmable calculator. This formulation is shown below:

$T E C=C i \cdot(1-S) \cdot W D H L / 2+C h \cdot R /(W D L)+C f \cdot R /(W D H L)+C 1 \cdot R /(W D H)$,

The authors will send anyone requesting it, a copy of the FORTRAN program to evaluate 
this case, using geometric programming. Solving the previous case for both $\mathrm{L}$ and $\mathrm{H}$, as design variables, we have:

$L_{\text {opt }}=126$ meters,$H_{o p t}=180$ meters $, Q_{o p t}=19,000$ tonnes,$T E C_{\text {opt }}=R 9030 /$ month In this case, the contributions to monthly costs are:

$\begin{array}{lll}\text { Cost Source } & \% & \% \times \text { TEC } \\ \text { Inventory } & 35 & 3185 \\ \text { Vertical Development } & 30 & 2660 \\ \text { Raise Stations } & 05 & 0525 \\ \text { Horizontal Development } & 30 & 2660 \\ \text { Total } & 100 & 9030\end{array}$

\section{CONCLUSION}

From the above we conclude that at optimum dimensions, the inventory costs in this situation are over $50 \%$ of the total monthly development costs. It therefore appears that the planning of shrink stope sizes with this approach could significantly reduce the "hidden" inventory costs usually ignored in shrink stope planning.

References:

[1] H. W. Tumbull, Theory of Equations, 5th ed., Oliver \& Boyd Publishers, Edinburgh, 1952, p. 166.

[2] R. E. D. Woolsey \& H. S. Swanson, Two Tutorials on Geometric Progtamming, in Operations Research For Immediate Application-A Quick \& Dirty Manual, Harper \& Row Publishers, NY, NY, 1975 , pp. 84-99. 